\section{“MENSAJE DEL VERDADERO PORTUGAL" LOS INTELECTUALES PORTUGUESES, LA IIa REPÚBLICA ESPAÑOLA Y EL FASCISMO IBÉRICO: PRENSA Y PROPAGANDA}

\author{
Alberto Pena Rodríguez \\ Facultad de Ciencias Sociales y de la Comunicación \\ Universidad de Vigo \\ alberto@uvigo.es
}

\section{"MESSAGE OF THE TRUE PORTUGAL" \\ THE PORTUGUESE INTELLECTUALS, THE SECOND SPANISH REPUBLIC AND THE IBERIAN FASCISM: PRESS AND PROPAGANDA}

Cómo citar este artículo/Citation: Pena Rodríguez, A. (2014). “'Mensaje del verdadero Portugal'. Los intelectuales portugueses, la IIa República española y el fascismo ibérico: prensa y propaganda". Arbor, 190 (766): a116. doi: http:// dx.doi.org/10.3989/arbor.2014.766n2008

Recibido: 11 septiembre 2012. Aceptado: 11 marzo 2014

RESUMEN: Este estudio pretende ahondar en algunos aspectos inéditos sobre el papel político jugado por los intelectuales portugueses en los inicios de la dictadura salazarista y su relación con España, especialmente en el marco de la Guerra Civil española. El Estado Novo de António de Oliveira Salazar contó con la colaboración de prestigiosos intelectuales, que aceptaron los nuevos presupuestos ideológicos del salazarismo y contribuyeron a su legitimación pública. Muchos intelectuales lusos se convirtieron, además, en propagandistas del movimiento franquista. Un caso paradigmático de su activismo a favor del fascismo ibérico, en el que se basa esta investigación, fue la campaña internacional que algunos de ellos realizaron a favor de la nueva España franquista. Esto provocó la respuesta de los intelectuales portugueses exiliados en España, que hicieron público el 4 de octubre de 1936 un manifiesto anti-fascista titulado "Mensaje del verdadero Portugal”.

PALABRAS CLAVE: Portugal; España; Salazarismo; Franquismo; Intelectuales; Guerra Civil; Propaganda; Prensa.
Copyright: (C) 2014 CSIC. Este es un artículo de acceso abierto distribuido bajo los términos de la licencia Creative Commons Attribution-Non Commercial (by-nc) Spain 3.0.

ABSTRACT: This article takes a closer look at some of the unexplored facets of Portuguese intellectuals' political role in the beginning of Salazar's dictatorship in the 1930s. Many prestigious Portuguese intellectuals, like Julio Dantas, José de Figueiredo or the Propaganda Ministry director and the "spirit policy" creator, the modernist writer António Ferro, accepted the new ideas of Salazar's regime and themselves became Iberian fascist propagandists. A paradigmatic case of their fascism activism, on which this research is based, was the international campaign run by some of them in favour of the new Spain of general Franco. This campaign caused a reaction by Portuguese intellectuals exiled in Spain, who published a manifesto entitled "Message of the true Portugal" in October 1936, which lambasted the alliance between the Portuguese government and the Spanish fascist movement.

KEYWORDS: Portugal; Spain; Salazar; Franco; Intellectuals; Spanish civil war; Propaganda; Press. 


\section{LOS INTELECTUALES PORTUGUESES Y EL ESTADO NOVO}

Según las estadísticas de la dictadura salazarista, en 1940 había censados 2718 intelectuales en Portugal, de los que tan solo el 2'2 \% eran mujeres. La mayoría estaban vinculados a profesiones liberales, a la administración pública o al comercio (Grácio, 1982; Madeira, 1996). El régimen los veía con cierto temor por su influencia social y su capacidad para modificar las formas de pensamiento y los valores oficiales del Estado Novo (Madeira, 1996). Salazar consideraba a la opinión pública un pilar fundamental de legitimación de cualquier gobierno, por eso entendía que “(...) nunca se deve perder, a bem da sua propria saúde, o controle (cursiva original) da sua formação" (Ferro, 1978). Su fobia a cualquier nueva forma de pensamiento, al libre análisis teórico de la realidad sin un compromiso nacionalista con el Estado Novo, lo llevaron a legitimar todos los mecanismos de censura posibles para vigilar y filtrar la prensa por su profundo temor a los contagios de la ideología comunista, que en algunos casos relacionaba con los intelectuales. La aprobación de la Constitución del Estado Novo en 1933 habilitaba al gobierno para censurar a la prensa. Salazar justificaba el control de los medios de comunicación porque, según su filosofía política, representaba “(...) a legítima defesa dos Estados livres, independentes, contra a grande desorientação do pensamento moderno, a revolução internacional da desordem. Eu não temo o grande jornalista desde que seja português e o demonstre. $\mathrm{O}$ que temo são os pequenos jornalistas que se desnacionalizam sem dar por isso, talvez por não estarem suficientemente armados para se defenderem de sedutoras e fáceis teorías (...)" (Ferro, 1978).

Los instrumentos represivos de la dictadura portuguesa impidieron que la universidad o cualquier otro foro de formación intelectual o cultural, así como la prensa, fuesen dirigidos por intelectuales no idóneos (Paulo, 1994). También trató de evitarse que en la Administración del Estado se instalasen elementos "nocivos" para la estructura político-ideológica del régimen con medidas legales específicas (Bastos, 1985). Estudiantes y profesores universitarios resultaron atenazados por la falta de libertad de expresión en las aulas y la imposición del modelo de pensamiento salazarista (Torgal, 1999). El salazarismo impuso sus ideas por la fuerza, a través del discurso visionario del dictador, que los medios afines orquestaron con intensas campañas de propaganda (Salazar, 1945; Martins, 1990). Salazar era un intelectual de prestigio cuyo pensamiento político fue transformado en el modelo teórico del régimen. Pero el salazarismo presuponía que los intelectuales, en general, tenían una cierta debilidad por el comunismo y el progresismo en general, dentro de un modo de vida totalmente burgués. Para evitar críticas deslegitimadoras y consolidar su proyecto de Estado, Salazar reprimió a los intelectuales desafectos (Torgal, 2003). Entre otras muchas acciones políticas, el salazarismo intentó atraer a los intelectuales hacia el Estado Novo a través del partido único del régimen, la União Nacional, para fundar las bases de su "dictadura intelectual", con un claro "designio doutrinário totalizante" (Braga da Cruz, 1988).

Salazar pretendía que los escritores y artistas actuasen subordinados al interés ideológico del Estado. Exigía de ellos el respeto absoluto por los intereses "nacionales" (léase del Estado Novo). Según manifestó al Diário da Manhã (el diario oficial de la dictadura) el 6 de marzo de 1937 el director del Secretariado de Propaganda Nacional (SPN), el literato modernista António Ferro, los intelectuales debían ser tan "útiles" al Estado "(...) como o operário, o comerciante ou industrial". Y, en la medida que se les sometía a esos "intereses", el dictador portugués estaba convencido de que así se protegía el espíritu nacional (Ferro, 1943). Según Ferro, "(...) Salazar é um grande homem de Estado, porque é, sobretudo, um grande artista. O seu Estado Novo, perfeito no seu equilibrio, nas suas linhas, é uma obra prima como por outras palavras já o disse Politis - de escultura política. Estejam tranquilos, pois, os artistas portugueses... É um camarada seu, um dos seus mais ilustres camaradas, que governa Portugal (...)".

Esta era una de las bases fundamentales de lo que Salazar llamó la "política do espírito", cuyo fin principal era trabajar por el renacimiento del arte populary fomentar un nacionalismo auténtico dentro de los estatutos del Estado Novo (Rosas, 1994; Torgal, 2008). Fue precisa una sistemática y pervertida revisión de la Historia para construir una nueva memoria colectiva (Ameal, 1956; Torgal, Mendes, Catroga, 1998; Ribeiro, 2010; Brandão, 2008). En septiembre de 1936, para intensificar la difusión de esta nueva historia, el Presidente de la Câmara de Oporto, el prestigioso intelectual salazarista Mendes Corrêa propuso fundar la Faculdade Livre de Estudos Portugueses, como complemento a la enseñanza de cursos sobre Historia de la Civilización e Historia de Portugal que se estaban impartiendo a los obreros de aquella ciudad en el Palácio de Cristal.

En mayo de 1936, se fundó la Academia Portuguesa da História por decreto del ministro de Educação Nacional, António Carneiro Pacheco, con un objetivo re- 
novador del pasado portugués. El primero de sus estatutos, hechos públicos en agosto de 1937, establecía como misión de la academia: "Estimular e coordenar os esforços tendentes á investigação, revisão e rectificação da história nacional no sentido superior da contribuição portuguesa para o progresso da civilização, bem como enriquecer a documentação dos inauferiveis direitos de Portugal" (cursiva en el original). Desde el Diário da Manhã se aplaude la iniciativa porque servirá para “(...) defender a nossa História de todos os seus inimigos - mistificadores engenhosos, demagogos de seita ou de partido, azedos e perversos derrotistas - é garantir, pura, íntegra e fecunda, a própria essência de Portugal eterno!". La historia, la ideología y la cultura eran, pues, una cuestión de Estado. Y los intelectuales, por imperativo legal, debían participar de este espíritu revisionista para el engrandecimiento de la Patria de Salazar. ${ }^{1}$

Por este motivo, el comunismo fue, durante los años treinta, uno de los anatemas fundamentales del salazarismo. El Estado Novo se atribuyó el papel de muro de contención frente a la Internacional Comunista, que supuestamente amenazaba la integridad nacional. Era el enemigo público número uno de la sociedad y la patria lusa (Matos, 2010 a y b). A los comunistas se les atribuía el fomento de teorías revolucionarias para intentar subvertir los fundamentos de la tradición y la cultura portuguesa, de dividir al país y de venderlo a los intereses extranjeros. El comunismo era también la mano negra culpable de los desórdenes sociales, de la ignorancia de los pueblos, de fragmentar la unidad familiar y nacional, de pervertir la moral cristiana y, sobre todo, de esclavizar al ser humano, según la propaganda salazarista. Era, por tanto, la encarnación del mal. El Estado Novo lo convirtió en un monstruo amenazante ante el que había que luchar unidos en torno a Salazar. Uno de los mensajes propagandísticos más repetido por el salazarismo, especialmente durante la Guerra Civil de España, era que Portugal estaba en peligro. El comunismo acechaba al otro lado de la frontera. Este alarmismo permanente en el que vivía Portugal, fue fundamental para fortalecer la deseada unidad frente a un enemigo externo cuya existencia e hipotéticas amenazas intentaban legitimar la política represiva del Estado Novo (Faria, 1995).

Cuando Salazar sufre el atentado fallido ejecutado por los opositores portugueses el 4 de julio de 1937 (Santana, 1976), la prensa portuguesa se convierte en un agitado altavoz anti-comunista. $Y$ el régimen aprovecha la ocasión para pedir el apoyo unánime para Salazar. Según el Diário de Lisboa, la sociedad tenía
“(...) o dever patriótico de estar a seu lado, sobretudo quando é necessário proteger a ordem, a lei, a disciplina e a concordia contra os seus naturais inimigos" (cursiva original).

El Estado Novo atacó directamente las conciencias de los intelectuales portugueses. Durante la Guerra Civil española (1936-1939), la presión del aparato de propaganda salazarista sobre los intelectuales fue permanente, al igual que ocurrió en la España franquista, que contó en sus inicios con la colaboración estratégica del Estado Novo (Pena Rodríguez, 2009, 2007, 1998; Trapiello, 2009; Malefakis, 1996, 511-540).

\section{LA CAMPAÑA DE LA ELITE INTELECTUAL SALAZARISTA CONTRA LA II REPÚBLICA ESPAÑOLA}

La elite intelectual portuguesa que apoyaba al Estado Novo no se mantuvo ajena a la campaña de propaganda de la dictadura salazarista contra la España "vermelha". Desde el Secretariado de Propaganda Nacional y estamentos académicos oficiales, desde las tribunas libres de la prensa o las conferencias públicas, la intelligentsia del régimen se comprometió con la causa del fascismo español. Eminentes profesores, personalidades académicas, artistas, prestigiosos científicos, poetas, escritores, abogados, médicos y profesionales con formación universitaria en general mostraron su adhesión al franquismo utilizando la prensa como plataforma divulgadora de todas sus iniciativas. Aunque fueron muchos los intelectuales lusos que publicaron textos a favor del general Franco, es imposible, no obstante, cuantificar el número de intelectuales portugueses que participaron en esta campaña, ni cuántos renunciaron a apoyar el fascismo español o se enfrentaron al Estado Novo haciendo contrapropaganda (Pena Rodríguez, 2007).

La reacción de los intelectuales afines al Estado Novo ante los acontecimientos bélicos del país vecino, fue un tácito compromiso con la propaganda de la dictadura. Sus intervenciones sobre la guerra, a través de artículos, manifiestos colectivos u otras formas de propaganda en la prensa lusa, tuvieron un peso específico en la batalla ideológica entre el "comunismo" y la "civilización occidental", que según Salazar, se estaba desarrollando en España. ${ }^{2}$ Durante el segundo semestre de 1936, la prensa portuguesa fue un clamor de denuncias de intelectuales portugueses, cuyo apasionamiento propagandístico fue perdiendo protagonismo a partir de mediados de 1937 (Pena Rodríguez, 2007). La Guerra Civil española representaba un desafío propagandístico para el salazarismo. Reaccionar o sucumbir al yugo comunista era la consigna que más repetían los intelectuales salazaristas en las páginas de los diarios 
lusos (Matos e Lemos, 2006). La propaganda del régimen instaba a reaccionar ante lo que se interpretaba como una premeditada destrucción de la cultura española por las "hordas marxistas" que también amenazaban a Portugal, de acuerdo con los argumentos de João Ameal en el Diário da Manhã el 29 de agosto de 1936.

Los intelectuales españoles eran un blanco preferente en el programa genocida de los comunistas, según esta misma versión. Augusto da Costa lo decía muy claro: en España, el gobierno de Madrid obliga a los hombres de letras a escoger entre ser comunistas o "desaparecer como parasitas inúteis" (Diário da Manhã, 1/09/1936). La mayoría optó por escoger esta segunda opción, tal y como lo describe la prensa lusa, que da por asesinados a muchos intelectuales $(O$ Século, 21/08/1936; A Voz, 25/08/1936; Diário de Lisboa, 10/12/1936). El escritor Dutra Faria es catastrofista en este aspecto ya en agosto de 1936. Entonces informó sobre la destrucción de “(...) a maior parte do tesouro artístico e intelectual de Espanha (...)" (Acção, 22/08/1936). Lo que le lleva a pensar a este autor que “(...) na Espanha, como na Rússia, o Comunismo foi uma experiência útil para os analfabetos (...)" (Acção, 22/08/1936). Mientras, el Diário de Notícias informa, el 13 de octubre de 1936, que todos los profesores son llevados al frente como carne de cañón.

La imagen que la prensa portuguesa ofrece de los rebeldes franquistas es radicalmente distinta. Los rectores de siete universidades en poder de los insurrectos en octubre de 1936 (Santiago de Compostela, Valladolid, Salamanca, Sevilla, Granada, Zaragoza y La Laguna) dirigen una carta al delegado portugués en el Instituto de Cooperación Intelectual de la Sociedad de Naciones, difundida por los periódicos lusos, para certificar su apoyo al franquismo como impulsor del "nuevo espíritu" de España. El Diário da Manhã señala que los sublevados respetan a los intelectuales que no tienen las mismas ideas y destaca que los escritores más ilustres están al lado del Alzamiento ( $D M$, 3/11/1936). Miguel de Unamuno es instrumentalizado como símbolo de esa propaganda (Rojas, 1995), al que atribuyen frases como las siguientes: "Se a Espanha sucumbir na luta contra os marxistas, a Europa sucumbirá também"; "estudei a pessoalidade de Salazar e cheguei a conclusão de que é um grande estadista tem inteligência e tem coração" (Acção, 22/08/1936). Por otra parte, a los líderes facciosos se les atribuye sensibilidad intelectual para apreciar los valores artísticos y culturales. El Diário de Notícias enumera, por ejemplo, las virtudes intelectuales del general Mola (DN, 12/11/1936). La defensa de la inteligencia y la cultura española eran, según esta versión de la propaganda portuguesa, uno de los objetivos del franquismo, mientras que el bando leal a la República hacía lo contrario. Por eso, la muerte del poeta Federico García Lorca, asesinado en Granada el 19 de agosto de 1936 por los falangistas, fue para la prensa del Estado Novo un crimen cometido "pelas milícias sanguinárias do Govêrno de Madrid" (DM, 10/10/1936; DN, 17/09/1936). O Século publica incluso que el escritor español fue asesinado en Cataluña junto a varios oficiales rebeldes (17/09/1936), y Dutra Faria confirma un mes después en Acção que fue fusilado porque “(...) o seu talento era uma afirmação de fascismo (...)" (19/09/1936).

António Ferro, director del Secretariado de Propaganda Nacional, faro de la cultura estado-novista e intelectual de prestigio, ${ }^{3}$ se pregunta en el Diário de Notícias qué pensarán los intelectuales de otros países ante el cadáver de Lorca, víctima de los "marxistas de Barcelona" (DN, 22/09/1936). En el medio citado, escribía regularmente el ideólogo salazarista João Ameal, que seguía las mismas pautas propagandísticas que el director del SPN, cargadas de demagogia y falsedades. En su artículo titulado "Optimismo" celebra las ventajas de la guerra española, cuya tragedia, según él, servía como penitencia para purificar España y crear un nuevo "orden" peninsular (DN, 31/10/1936).

Los integralitas Hipólito Raposo y Alfredo Pimenta también se destacaron como propagandistas de la causa franquista en Portugal. ${ }^{4}$ Publicaron decenas de columnas periodísticas en el diario católico $A$ Voz. Su director, Fernando de Souza, propuso al inicio de la guerra unificar los criterios informativos de los diarios portugueses sobre el conflicto para crear un "frente común" contra la propaganda comunista (30/07/1936). Hipólito Raposo fue, precisamente, el autor de un manifiesto, publicado el 5 de agosto de 1936, en el que pedía algo que fue habitual en los artículos escritos por los intelectuales salazaristas: la unidad de la inteligencia de Portugal para luchar contra las influencias del comunismo en la cultura portuguesa:

“A nossa posição (...) deve ser já de protesto e de luta intelectual contra a esperança e o júbilo intrépido dos comunistas de Portugal que alegremente deixaram de ser portugueses para ser espanhóis ou russos. Urge que a Inteligencia portuguesa, intérprete e pregoiera do verdadeiro sentimento nacional, pratique um acto de independência e de nobreza, condenando pela mais energica repulsa, essa monstruosa aspiração em que se afogam em sangue inocente as mais preciosas flores do espirito humano. (...) Pertença ao Governo o cuidado e a responsabilidade da defesa militar; mas 
devemos nós assumir, pelo destino que nos cabe, o encargo do protesto vivo e ardente contra a legião do ódio e do crime que pretende conquistar e escravizar Portugal. (...) Escritores, professores, artistas, agricultores, sacerdotes, advogados, médicos, engenheiros, industriais, operarios que sois pela vida e pela honra de Portugal dizei-o alto e claro. Não vos caleis para não consentirdes. Veio a hora de fazer o alarde das almas. Silencio não!”. (A Voz, no 3396, 05/08/1936).

El manifiesto tuvo la respuesta favorable de numerosos intelectuales que compartían el punto de vista de Raposo en artículos publicados en $A$ Voz. A. Cordeiro Ramos, ex alumno de Salazar en Coimbra, fue tajante en su contestación: "Presente e presente para todas as eventualidades e para todos os sacrificios, pondo na luta da ordem contra a desordem, nesta guerra de vida ou de morte contra a defesa da Patria e do seu património material e moral. (...) Quem não é por nós é contra nós" ( $A$ Voz, 7/08/1936). Alfredo Pimenta disponía de una tribuna libre antetitulada "Coisas de Espanha!". Desde esta plataforma periodística defiende posiciones ultraconservadoras y arremete contra todos los que respaldan cualquier forma de neutralidad en la guerra española, rechazando el principio de no intervención porque eso suponía, según su criterio, darle alas al comunismo ( $A$ Voz, 7/08/1936). Pimenta valora especialmente los méritos de la "reconstrucción moral" del ejército español, que decidió implantar el crucifijo en las escuelas, revisó los manuales escolares y obligaba a los soldados a hacer el juramento religioso ( $A$ Voz, 10/10/1936). “(...) O reconhecimento expresso de Deus é imprescindível nos Estados. Deus não se compadece com o reconhecimento tácito, porque ele não precissa de disfarces, nem tolera maquiavelices. É-lhe devido respeito formal e culto claro. Se o Poder não afirma expressamente, formalmente, aquele respeito, e não garante, estimula e segue este culto, esse Poder será tudo, mas não será católico, e não sendo católico desserve a Ordem social (...)", sentencia Pimenta, que llama la atención sobre el asesinato de intelectuales católicos en España y proclama la inocencia de los insurgentes en el ataque a la elite española: “(...) Ninguém aponta um nome de relevo, na inteligencia ou no saber, na arte, na industria, no comércio, em qualquer das múltiplas manifestações da vida espanhola que tenha sido vítima de qualquer violencia por parte dos nacionalistas. Não há um para amostra ou exemplo. Todos os que alinham, tombados, na vala imensa do cemiterio sem fim, e foram alguma coisa no mundo, todos esses são vítimas da furia republicana e marxista! (...)" (A Voz, 31/05/1937).
Alfredo Pimenta es profundamente radical en sus puntos de vista y exige que toda la prensa portuguesa sea unánime en la propaganda del fascismo español frente al gobierno de Madrid. A su vez, el intelectual integralista se muestra satisfecho con la posición adoptada por la prensa de Lisboa, especialmente con A Voz, el Diário da Manhã y el Diário de Notícias: “(...) todos eles afirmam a sua simpatia pela causa da ordem social representanda pelo Exército e condenam sem rebuço, formalmente, as infamias dos sicarios marxistas" (26/08/1936). Pero Pimenta no piensa lo mismo de los periódicos de la ciudad de Oporto, a los que critica duramente por sus reiterados silencios sobre las victorias del general Franco. Según él, el Comércio do Porto y $O$ Primeiro de Janeiro no prestan atención a lo que está ocurriendo en España. Del primero apunta que es un "jornal bolchevisante" y, el segundo, lo cataloga como el órgano del "reviralho nortenho" (ibídem).

Júlio Dantas fue otro de los más prestigiosos intelectuales portugueses que se alineó con la propaganda del Estado Novo contra el gobierno español. ${ }^{5}$ Dantas era un académico sobresaliente, socio de numerosos organismos científicos nacionales e internacionales y representante de Portugal en el Instituto de Cooperación Intelectual de la Sociedad de Naciones (precedente de la actual UNESCO). Sus artículos relacionados con la Guerra Civil española fueron publicados, principalmente, en $O$ Primeiro de Janeiro y el Comércio do Porto. A través de ellos, hace unas consideraciones muy eruditas sobre el conflicto. Lo mismo realiza una atrevida e intencionada comparación entre la invasión francesa y la invasión rusa de la Península (OPJ, 10/09/1936), que critica la política exterior francesa (OPJ, 24/09/1936) o discute la naturaleza del pacto de no intervención, que consideraba favorable a los leales (OPJ, 1/10/1936).

Dantas encabezó la campaña internacional de los intelectuales salazaristas contra el gobierno legítimo español, acusándolo de propiciar el genocidio de escritores y de la destrucción sistemática del patrimonio artístico y cultural de España. A finales de septiembre de 1936, Júlio Dantas solicitó la intervención de la Sociedad de Naciones en este tema (DN, 21/09/1936). El 6 de octubre, en la sesión de la Academia das Ciencias portuguesa, el escritor portugués habló, como presidente de la sección de Letras, sobre la guerra. Durante su exposición, el académico solicitó que el organismo se interesase, a través de la acción diplomática del gobierno portugués, por la situación de los intelectuales españoles, así como enviar a las academias españolas una carta con la "(...) expressão comovida e fraterna da sua solidariedade moral" (DN, 8/10/1936). Propuestas que 
fueron aprobadas por unanimidad tras las intervenciones favorables de otros miembros del organismo, como Pedro José da Cunha, Gustavo Cordeiro Ramos, Queiroz Velozo, Pereira Forjaz y José de Figueiredo.

La preocupación expresada por Dantas persuadió a otros intelectuales, que solicitaron la unión de todas las "forças morais" contra la destrucción del tesoro artístico en España (Comércio do Porto, 22/10/1936). Aunque algunos de ellos ya se habían posicionado públicamente mucho antes. Teles Baltasar, por ejemplo, se horrorizó cuando la prensa portuguesa informó sobre los bombardeos "marxistas" en la catedral de Zaragoza. Acción que este intelectual calificó de atentado contra todos los católicos. Por eso hace un ruego a la Virgen del Pilar para que "(...) se digne conceder à nobre Espanha o triunfo da ordem, da paz, da justiça, da prosperidade e da Religião" ( $A$ Voz, 7/08/1936). Y José de Faria Machado utiliza un tono aún más apocalíptico en su llamamiento a los intelectuales portugueses el 24 de agosto de 1936, pidiendo al director de $A$ Voz que convierta su periódico en el gran altavoz que "(...) grite ao Pais e ao Mundo inteiro, a revolta, a repulsa dos escritores e artistas portugueses perante tamanha barbaridade" ( $A$ Voz, 24/08/1936). Faria Machado pretende que la elite del Estado Novo aparque sus diferencias políticas y concentre sus esfuerzos en protestar por los asesinatos comunistas en territorio español. Con su llamamiento, las páginas de $A$ Voz se transformarían en un antológico escaparate de artículos de intelectuales que deciden actuar contra los horrores del "comunismo" español (ibídem).

Al día siguiente de la publicación del apelo de Faria Machado, aparecen varias cartas de apoyo. Alfredo Cândido propone rezar por los escritores españoles muertos y que la reacción de la intelectualidad portuguesa se ponga en conocimiento de los principales centros de cultura de otros países para que el horror comunista "(...) fique marcado com o ferrete eterno da nossa mais veemente repulsa" ( $A$ Voz, 25/08/1936). A esta carta le siguieron otras muestras de adhesión en días sucesivos de destacados propagandistas del salazarismo, como Fernando Campos, A. Paulo Machado o Leão Ramos Ascensão. Este último, en su artículo "Quem se cala perante estas atrocidades. Quem aprova estas infamias?", expresa su profundo enojo por la incredulidad de los que dudan sobre la veracidad de las informaciones relacionadas con la "barbarie marxista" e insiste en que la prensa portuguesa debe reproducir más documentos sobre los crímenes del bando leal (A Voz, 29/08/1936). En cambio, Agro Ferreira defendía que, para proteger la cristiandad y la latinidad, era necesario luchar contra el alineamiento de Francia con Rusia en la guerra. Para tratar de influir en la actitud francesa, Ferreira era partidario de hacer un nuevo manifiesto: "Este manifesto, documentado com o relato dos acontecimentos, deveria ser asinado pelos vultos mais representativos do Professorado, Literatura, Jornalismo e Sindicatos Operários, redigido em português, espanhol, inglês e francês e dirigido a todos os povos de Europa e do resto do Mundo, principalmente da América (...)" (A Voz, 2/09/1936).

Numerosas instituciones académicas portuguesas emitieron resoluciones anti-republicanas que gozaron de una sensacional promoción periodística. La Academia Nacional de Belas Artes, presidida por José de Figueiredo, aprobó el 13 de octubre de 1936 una moción de protesta para rechazar de plano el vandalismo comunista en España. El manifiesto fue firmado por los siguientes vocales: los escritores Reinaldo dos Santos, Matos Sequeira, Xavier da Costa, Luiz Keil y João Couto; los escultores Francisco Franco, João da Silva y Diogo de Macedo; los pintores Sousa Lopes y Varela Aldemira; y los arquitectos Guilherme Rebelo de Andrade, Paulino Montez y Luís Ortigão Burnay $(D M, 14 / 10 / 1936)$. El escrito de denuncia de este organismo fue publicado por el $A B C$ de Sevilla y el ex director del Museo del Prado, Fernando de Sotomayor, envió una carta dirigida al director de la academia lusa, reproducida en el Diário da Manhã y el Diário de Notícias, agradeciendo “(...) el espíritu de solidaridad y simpatía que anima tan honroso documento hacia los que en España luchan contra la barbarie y la incultura" (DN y $D M, 27 / 11 / 1936)$.

La Associação de Médicos Católicos Portugueses se sumó al conjunto de protestas formales expresando su apoyo incondicional al "exército salvador" (DM, 19/10/1936), y la Revista Portuguesa de Arqueologia abre el tercer volumen de su colección con un artículo del epigrafista José Maria Cordeiro de Sousa que pone en evidencia la masacre de los "valores intelectuais" y la "riqueza monumental" española a manos de los "marxistas" (A Voz, 18/12/1936). El Instituto Português de Arqueologia, História e Etnografia respaldó también por unanimidad una nueva moción sobre este asunto, presentada en febrero de 1937 por el profesor João Martins da Silva Marques, que decía lo siguiente:

"Considerando que na guerra que assola o país vizinho os comunistas e seus aliados têm praticado, sistematicamente e repetidamente, assassinios, violações, torturas, incendios, roubos, etc., enfim das mais horriveis atrocidades fisicas e morais; considerando que os mais monstruosos ultrages ás pessoas atingem, 
de preferencia, classes e elementos indefesos e que, por isso mesmo deveriam ser os mais respeitados, como mulheres, crianças, presos, prisioneiros, refens, sacerdotes, religiosos, etc.; considerando que, simultaneamente com tais crimes, os mesmos comunistas e seus aliados têm sempre defendido com cinismo a dissolução de todos os principios e sentimentos éticoreligiosos que constituem o mais sagrado patrimonio humano; considerando que a tudo isto se junta a destruição e rapina metodicas de igrejas, monumentos, museus, arquivos, bibliotecas e obras de arte e o assassinio de individualidades científicas, literarias e artisticas, etc.: o Instituto Português de Arqueologia, Historia e Etnografia lavra contra tais crimes o seu mais veemente protesto e faz votos pela vitoria da nação espanhola e, atravês dela, da civilização cristã e europeia, e resolve dar conhecimento dessa moção as suas congéneres espanholas, logo que as circunstancias o permitam"." (O Século, no 19729, 19/02/1937, 7).

\section{EL MANIFIESTO CONTRA LA "BARBARIE COMUNISTA" DE ANTÓNIO FERRO}

Uno de los momentos más importantes de la batalla propagandística desarrollada por los intelectuales portugueses contra los supuestos "crímenes" del ejército leal a la IIa República ocurrió cuando, a instancias del Secretariado de Propaganda Nacional, varios centenares de ellos firman un manifiesto contra la "barbarie comunista" en España. El origen de este Ilamamiento público de los máximos representantes de la cultura del Estado Novo está en un artículo publicado por António Ferro en el Diário de Notícias el 22 de septiembre de 1936, titulado “Quem protesta?". Desde esta tribuna, el director del SPN ataca directamente a los intelectuales izquierdistas franceses, españoles, americanos, ingleses o portugueses. Según su argumento, estos siempre condenaron cualquier agresión contra la inteligencia; sin embargo, callan en el caso de España. Y se pregunta: “(...) Onde estavam quando as balas marxistas, bebedas de sangue e ódio, fizeram cair para sempre esse intelectual puro que se chamou Ramiro de Maeztu, que nunca teve outras armas que não fossem as suas ideias? Porque se calam Malraux, Cassou, Huxley, Sinclair Lewis, Thomaz Mann e os seus generosos confrades diante do assassínio de D. Jacinto Benavente (sic), premio Nobel e gloria universal do teatro? (...)". ${ }^{6}$ Ferro arremete también contra los intelectuales que prefieren observar pasivamente a actuar, acusándoles de ser cómplices del genocidio, e incita a la reacción:

“(...) Hipócritas, ou inconscientes! Continuem a calarse perante os fuzilamentos da melhor gente de Madrid ou Barcelona, daquela que formava o grupo familiar da Espanha mental a sua imagem mais simpática e suges- tiva. Justifiquem, até, se quiserem, com argumentos sinistros, os crimes dos marxistas. Mas não se admirem se perdermos o respeito pela sua inteligencia estupida (cursiva original), se lhes arrancarmos das mãos sangrentas, destruidoras, o diploma de criadores!... Ou repudiam, e com urgencia, as matanças de Espanha, as execuções sumarias dos intelectuais, seus irmãos, (registem-se para exemplo, as nobres reportagens dos correpondentes de guerra portugueses), ou não lhes servirá de nada o talento ou o genio. Poderão escrever maravilhas, que as suas penas havemos de ve-las sempre tintas de sangue... Responder-nos-ão que aos escritores e jornalistas brancos (cursiva original) competiria, desta vez, a iniciativa do protesto... Sem duvida. Foi precissamente esse dever que nos levou a escrever este artigo (talvez desmancha-prazeres) (cursiva original) e assiná-lo. É possivel que o nosso protesto isolado, que á nossa assinatura não se juntem outras. Que cada um fique em paz com a sua consciencia... A nossa, pelo menos, deixou de nos pedir contas..." (Diário de Notícias, no 25372, 22/09/1936, p. 1).

De forma inmediata, en una carta abierta a António Ferro, el salazarista Albino Forjaz de Sampaio lanza la idea de difundir internacionalmente un manifiesto colectivo encabezado por el director del aparato de propaganda del Estado Novo, en el que participen "todos os que dia a dia remam nesta galera do pensamento e do sonho" (DN, 22/09/1936). El subdirector del SPN, António Eça de Queiroz (hijo del popular escritor del realismo literario portugués), propuso a través de un artículo publicado en el Jornal do Comércio e das Colónias que el manifiesto fuese remitido al Instituto de Cooperación Intelectual de la Sociedad de Naciones. Según el Diário da Manhã, el espíritu del artículo de Ferro “(...) estava latente na alma de todos os homens de letras e artistas portugueses que não pactam com criminosos (...)" (DM, 2/10/1936). El creador de la "política do espírito" afirma entonces al semanario nacionalista Acção que todos los intelectuales lusos tenían el deber de protestar contra los crímenes del comunismo (DM, ibídem). El manifiesto, publicado el 10 de octubre de 1936 y que reproducimos íntegro por su singular valor histórico, decía lo siguiente:

"Alguns dos mais ilustres escritores, artistas e jornalistas espanhois do nosso tempo, tudo leva a crêr que se encontram detidos nas prisões de Madrid, de Barcelona, de Valencia ou de Alicante, pelo crime ou meras suspeitas de não pensar conforme das doutrinas representandas pelo govêrno que domina algumas regiões de Espanha. Outros foram executados, sem culpa ou aparencias de julgamento; todos os que sobrevivem e não puderam acolher-se á hospitalidade de paises estrangeiros ou refugiar-se nas regiões em que o Exército conseguiu impôr uma ordem 
civilizada correm o risco de serem julgados por tribunais odiosos, constituidos por individuos fanatizados pelas mais ásperas paixões políticas e sem cultura para avaliarem o que representa como atentado ao Espirito a execução de alguns dos maiores valores da Espanha actual.

Tem-se destruido, por obediencia a uma determinação sistemática, metodicamente, diabolicamente executada, o patrimonio artistico da Espanha, cujo valor histórico e humano têm ás vezes aspectos que parecem sobrenaturais. E, nessa obra destruidora, em odio tenacissimo a tudo o que é nobre e superior, seja a pedra redilhada duma catedral ou dum castelo de outrora, a virtude duma mulher ou a grandeza dum heroi, julga ver-se a intenção satanica de destruir tudo, com o objectivo infantil de construir do "nada" as vagas aspirações arquitectadas em momentos de alucinação.

Aperta-se o coração dos homens ao assistir a êste espectáculo de ferocidade sem precedentes; e, quando se pensa que, não contentes em destruir o passado nas criações que lhe sobreviveram e matar o Presente das suas realidades mais vigorosas se intenta destruir por antecipação o Futuro nas suas obras, executando os escritores e artistas que deveriam realizá-lo nas suas aspirações criadoras, deve-se perguntar se os homens cultos, conscientes das suas responsabilidades, têm o direito a assistir a esa obra maldita de confusão da morte.

Se o Instituto de Cooperação Intelectual da S.D.N. se empenha em não atraiçoar os fins da sua constituição, mais do que a nenhum outro organismo the compete a honra de intervir, que mais não seja que para fixar um protesto que se ouça em todo o mundo. Os signatarios, escritores, jornalistas e artistas portugueses, já que outros de outras nações não quiseram tirar-Ihe a honra desta iniciativa, antecipandose, sugerem ao Instituto de Cooperação Intelectual da Sociedade das Nações a necessidade urgente de correr em socorro dos seus irmãos de Espanha, e, perante êle, protestam com dolorosa indignação contra o furor bárbaro que ameaça subverter de todo a flor mais alta da inteligencia, da cultura e da arte da Espanha moderna, e as proprias condições da sua colaboração no futuro das nações". (Diário da Manhã, no 1968, 10/10/1936, 1 y 7 ).

El texto de los intelectuales portugueses "contra a barbarie comunista em Espanha" fue difundido ampliamente por los diarios lisboetas, con la excepción clamorosa y habitual del opositor República y la del Diário de Lisboa. Desde el 2 hasta el 20 de octubre, el Sindicato Nacional dos Jornalistas recogió las adhesiones de numerosos intelectuales que estamparon su firma antes de enviar el texto a Ginebra. Casi todos los días, los diarios (en especial el órgano de la União Nacional, el Diário da Manhã) publicaban noticias sobre las nuevas incorporaciones a la lista oficial de adhesiones. Los primeros en sumarse a la iniciativa fueron: Eugénio de Castro, Eduardo Schwalbach, Agostinho de Campos, António Correia de Oliveira, Joaquim Manso, Pestana Reis, Caetano Beirão, António Soares, Teresa Leitão de Barros, Fernando Campos, Capitão Henrique Galvão, Albino Forjaz de Sampaio, Canto da Maia, Jorge Segurado, Silva Tavares, Manuel Múrias, António Lopes Riberio, Artur Maciel, Carlos Queiroz, Francisco Lage, Augusto Cunha, Armando Boaventura, Vitoriano Braga, Fernando Pamplona, Domingos Mascarenhas y Augusto Ferreira Gomes. La lista, sin embargo, era interminable, formada por varios centenares de artistas, periodistas, escritores y toda clase de intelectuales (DM, 2/10/1936).

La prensa internacional también se hizo eco de la iniciativa propagandística de António Ferro. Algunos periódicos, como el Diário Português de Brasil o algunos medios alemanes elogiaron la actitud de los intelectuales portugueses (DN, 8 y 11/11/1936). El aparato de propaganda luso buscó el apoyo de otros intelectuales europeos de prestigio para que suscribieran las consignas del Estado Novo. El escritor francés Jerôme Tharaud, que fue invitado por el SPN a visitar el país para conocer el "nuevo" Portugal en 1936, aplaudió efusivamente la campaña y prometió llevar a cabo una iniciativa similar en Francia (DM, 2/10/1936). Durante los momentos más difíciles para la diplomacia portuguesa en Europa por su política de apoyo al franquismo, recibió el respaldo de Jerôme y Jean Tharaud, que defendieron el derecho de Portugal a no firmar el Acuerdo de No-Intervención para favorecer los intereses de los militares sublevados en España (O Século, 19/10/1936). Uno de los intelectuales que, con más frecuencia, utilizó el gobierno portugués como referente de la adhesión de los intelectuales a su política, fue el catedrático suizo y conde Gonzague de Reynold, que recibió uno de los premios literarios del SPN en 1937 por su libro Portugal, dedicado a promocionar las excelencias del sistema autoritario portugués con menciones concretas a la coyuntura política del momento ( $D N$, 28/05/1937). Reynold defendió la tesis de Salazar respecto a la España republicana: “(...) uma Espanha Vermelha poderia ser, de facto, para a pequena república lusitana, a absorção, a perda da sua liberdade, a ruina material e moral, e a ruina no sangue" (Acção, 6/02/1937). 


\section{LA CONTRAPROPAGANDA DE LOS OPOSITORES A SALAZAR: EL “MENSAJE DEL VERDADERO PORTUGAL"}

La campaña internacional de los intelectuales salazaristas tuvo una inmediata respuesta por parte de los exiliados políticos portugueses en España. Prestigiosas personalidades de la cultura y la política portuguesa exiliadas en la zona republicana, publicaron en la prensa española un manifiesto contra la dictadura del Estado Novo y su alianza con los militares sublevados contra el gobierno legítimo español.

Titulado como el "Mensaje del verdadero Portugal", fue firmado por Alberto de Moura Pinto, antiguo ministro de Justicia; Alberto Alexandrino dos Santos, antiguo capitán del ejército y secretario del gobierno de Huila (Angola); Armando Zuzarte Cortesão, escritor y antiguo agente general de las Colónias; Fernando de Utra Machado, antiguo ministro de Colonias y gobernador general de Angola; Gonçalo de Reparaz (junior), catedrático y escritor; Israel Anahory, antiguo cónsul; Francisco Oliveira Pio, antiguo capitán del ejército y administrador de Alto Zambeze (Angola); Jaime de Morais, antiguo gobernador general de Angola y de la India Portuguesa; Júlio César de Almeida, antiguo cónsul de Portugal y capitán del ejército; Manuel Firmo, antiguo directivo del Sindicato Ferroviario y Jaime Zuzarte Cortezão, historiador, miembro de la Académia de Ciências, ex director de la Biblioteca Nacional de Lisboa y antiguo diputado de la República.

El manifiesto, publicado el 4 y 5 de octubre en diversos periódicos españoles, ataca la alianza de la dictadura portuguesa con el fascismo español, llama la atención sobre los posibles riesgos para la independencia de Portugal, defiende la soberanía española y expresa sus temores por la pérdida de las colonias ultramarinas lusas:

"Los abajo firmantes, portugueses, que por el hecho de vivir en el extranjero pueden ejercer el derecho de expresar libremente sus opiniones, alarmados con la súbita mudanza de orientación que la dictadura portuguesa está imprimiendo, sin previo asentimiento nacional, a su política exterior, con amenaza para la seguridad de la patria y conservación de su patrimonio ultramarino, se sienten en el indeclinable y urgente deber de declarar lo que sigue:

10.- Tan celosos defensores de la independencia nacional como respetadores de la soberanía y de las libertades democráticas de los otros países, repudian toda injerencia del Estado portugués en la vida política de cualquier otro Estado, mucho más cuando, en el caso actual de España, se ejerce con escandaloso alarde contra su Gobierno legítimo, elegido por un sufragio universal tan insospechadamente expresado.
20.- Profundamente convencidos de que la independencia nacional está intimamente ligada a la conservación del patrimonio ultramarino portugués, gravemente amenazado por codicias ajenas, entienden que es indispensable mantener el sistema tradicional de nuestras relaciones exteriores, fundado en la alianza lusoinglesa (...).

4․- Igualmente seguros de que interpretan los sentimientos del pueblo portugués y el sentido de su historia como un esfuerzo constante y progresivo para la conquista de las libertades democráticas, proclaman también la necesidad de mantener con la democracia francesa una política de amistad y aproximación (...).

50.- En la hora trágica que ensombrece a toda España y lanza sobre el mundo la amenaza de más vastas divisiones y luchas, la solidaridad fraternal de los firmantes está con aquellos que defienden el trabajo creador y la libre soberanía del pueblo contra la usurpación opresora de las clases oligárquicas.

6o.- Finalmente, están segurísimos de que el pueblo portugués, si pudiese expresarse libremente, ratificaría casi por unanimidad estas declaraciones." (A Voz, no $3474,23 / 10 / 1936$, p. 1).

La prensa portuguesa al servicio del salazarismo instrumentalizó el manifiesto. Ante la opinión pública, lo presentó como la confirmación de uno de los principales argumentos de la propaganda salazarista contra sus opositores: que el gobierno legítimo español pretendía la unión ibérica y, para ello, se servía de los "traidores", "vis" e "indesejáveis" exiliados, en su "aventura conspiratória" contra Portugal (DM, 23/10/1936). El abogado Ary dos Santos exigió la instantánea expulsión de Jaime Cortezão de la Academia das Ciências de Lisboa, de la que era miembro, por firmar el escrito. Ary dos Santos explica al presidente del organismo, el general Aquiles Machado, que “(...) a doutíssima Academia não pode tolerar no seu seio traidores á Pátria" (DN, 23/10/1936). En en su libro de propaganda sobre la guerra, titulado Dom Quixote Bolchevick, explica que los firmantes del manifiesto eran "tartufos" que vivían en España "(...) sem fazerem nada de útil ou proveitoso, mastigando as esmolas ou os subsídios que de Portugal e da Rússia lhe enviabam certos senhores que mereciam estar dependurados pelos fundilhos das calças - vejam como sou humano - nos candeeiros da iluminação pública (...)" (Santos, 1936). Asimismo, el presidente de los Sindicatos Nacionais Ferroviários, Mateus Gregório Cruz, acusa a otro de los firmantes del manifiesto antisalazarista, Manuel Firmo, de arrogarse un cargo que no le correspondía (DN, 25/10/1936). El Diário de Notícias reprodujo la portada del número de El Sol donde 
se publicó el documento, calificándolo de “(...) acervo de criminosas insinuações e de torpes mentiras forjadas por um telebroso internacionalismo que serve as mil maravilhas os interesses políticos de Moscovo (...)" (DN, 22/10/1936). Además, un denominado Comité Popular de Defesa Nacional editó un informe de más de 100 páginas titulado A Espanha Vermelha contra Portugal. Portugueses traidores ao lado dos sinistros obreiros das Repúblicas Soviéticas da Iberia, donde se reproducen varios artículos de la prensa lusa sobre la trama del gobierno de Azaña para entregarle armas a los exiliados portugueses en 1932.

Los refugiados políticos portugueses en España y Francia llevaron a cabo una particular campaña contra el gobierno de Salazar. El ex presidente de la República portuguesa, Bernardino Machado, miembro del denominado Comité de Paris, fue autor de varios manifiestos, de los que se imprimieron ejemplares clandestinos en Lisboa. ${ }^{7}$ En septiembre 1937, dirigió una carta de protesta ante el presidente de la Sociedad de Naciones contra la ayuda de Berlín, Roma y Lisboa a los insurrectos, publicada en el órgano del Frente Popular Portugués (FPP) en el exterior, Unir. En enero de 1938, B. Machado difundió un nuevo manifiesto contra la "esclavización" del pueblo portugués (Machado, 1979). Los intelectuales portugueses emigrados participaron también en el itinerante II Congreso Internacional de Escritores Antifascistas, celebrado en Valencia, Madrid y Paris. En calidad de secretario de la sección portuguesa de la Asociación Internacional para la Defensa de la Cultura, intervino Jaime Cortezão. En julio de 1937, en la capital del Turia, el ex director de la Biblioteca Nacional de Portugal pidió el firme compromiso de todos para "(...) auxiliar con las armas o con la pluma la causa del pueblo español (...)" (Schneider, 1978). Y explica entonces que los exiliados portugueses tienen en funcionamiento una radio clandestina, gestionada por el Frente Popular Português, y editan de forma secreta numerosos periódicos para informar al pueblo portugués sobre el "verdadero" significado de la guerra de España.

El órgano del Frente Popular Português, editado en Paris con el respaldo de la Federação dos Emigrados Portugueses em França y el Comité Português de Ajuda ao Povo Espanhol, comenzó a publicarse en el verano de 1937 con financiación del gobierno de Madrid (Oliveira, 1988). El Unir se publicaba en portugués, con una amplia cobertura del conflicto español y sus consecuencias para Portugal. Entre sus colaboradores se encontraban Novais Teixeira, Jaime Brasil e Israel Anahory, dirigidos por el ex presidente de la República portuguesa José Domingues dos Santos. En agosto de 1938, la Delegación del Frente Popular Portugués en Madrid editó el impreso Revolución, un periódico de dos páginas redactado en castellano, del que solo se publicó un número extraordinario, en el que se hacía un recorrido por los "doce años de dictadura en Portugal" y se hacía pública la solidaridad de los exiliados portugueses con el gobierno de la IIạ República y "los heroicos combatientes de la libertad del mundo". Su editor era el propio José Domingues dos Santos, que fue uno de los peores látigos propagandísticos contra Salazar en Francia. El político exiliado acusaba al dictador de abrir las puertas de Portugal al imperialismo español (DM, 16/01/1939). A principios de diciembre de 1936, José D. dos Santos fundó la revista France-Espagne, que utilizaba técnicas de desinformación. Sus contenidos se referían exclusivamente a la guerra española y su intención era confundir a los lectores de otra publicación homónima subvencionada por los agentes franquistas en Paris. France-Espagne, escrita en francés, era extremadamente crítica con los líderes franquistas y el gobierno portugués. Según el Diário da Manhã, su primer número fue muy promocionado en la capital francesa (DM, 12/12/1936). Entre 1938 y 1940, los exiliados en Paris publicaron también Liberdade. Jornal Antifascista Português, que abre un debate sobre el modelo democrático que deseaban para Portugal.

Además de la campaña de propaganda realizada por las más destacadas personalidades políticas e intelectuales portuguesas en el exterior, pertenecientes al Frente Popular Portugués o al Comité de Paris, debemos mencionar también las acciones desarrolladas por la Federação de Anarquistas Portugueses Exiliados (FAPE), que creó una emisora conocida como Rádio Fantasma, que emitía hacia Portugal desde España, y el periódico Rebelião, editado por José Rodrigues Reboredo (Oliveira, 1988). Es también reseñable el papel de intelectuales opositores al régimen desde dentro de Portugal. Varias revistas y periódicos vinculados al movimiento neo-realista portugués, principalmente O Diabo (1934-1940), Manifesto (1936-1938), Altitude (1939) y Sol Nascente (1937-1940) denunciaron la muerte de García Lorca y el bombardeo de Guernica por parte del bando fascista e hicieron críticas veladas al Estado Novo por su ayuda al franquismo. Entre los colaboradores de estas publicaciones se encontraban escritores de referencia en la literatura portuguesa contemporánea, como Miguel Torga, José Gomes Ferreira, Joaquim Namorado o Eugénio de Andrade. 


\section{CONCLUSIONES}

Los intelectuales portugueses jugaron un papel relevante durante el período de la IIa República y la Guerra Civil española. Tanto los que se mostraron afines a la dictadura en Portugal como los que se exiliaron en España, intentaron influir en las relaciones ibéricas y el destino político de ambos países peninsulares. Dentro de una campaña orquestada para desacreditar al gobierno de la II República, el literato António Ferro, director del aparato de propaganda del Estado Novo, promovió un manifiesto internacional de intelectuales a favor del fascismo español. Por su parte, los intelectuales y políticos portugueses anti-salazaristas exiliados en España y Francia respondieron a esta campaña con diversas acciones propagandísticas, entre las que destacó un manifiesto publicado en la prensa española titulado "Mensaje del verdadero Portugal", que se convirtió en el símbolo de la contrapropaganda antifascista portuguesa durante la Guerra Civil española.

\section{NOTAS}

1 El Decreto-ley no 1941, del 11de abril de 1936, que establece las bases del Ministério de Educação Nacional, obliga a los profesores a cooperar en la formación del "espírito nacional" por encima de cualquier criterio científico. Además, regula la utilización de un único manual de historia en los colegios e institutos de todo el país.

2 Nota oficiosa de la Presidencia del Conselho publicada en la prensa portuguesa el 9 de septiembre de 1936. (1939): Véase Portugal ante la Guerra Civil de España. Documentos y notas, Lisboa: Ediciones del SPN, 27-31.

3 António Ferro (1895-1957) tuvo una trayectoria intelectual muy singular. Desde muy temprana edad, manifestó sus dotes literarias y su debilidad por el periodismo. Se vinculó al movimiento modernista portugués. Fue editor de la revista modernista Orpheu (1915) y publicó, en esta primera etapa, varias obras, como Misal de Trovas (1912) o Cartas do Marinho (1919), que era una colección de sus crónicas publicadas en O Século. Después de una estancia en Angola como miliciano, vuelve a Portugal con una disposición más participativa en la vida política, haciendo una defensa del nacionalismo y a favor de la intervención del Estado en la cultura. En 1921, dirige la revista Ilustração Portuguesa, donde queda patente su carácter nacionalista. En 1922 se establece en Brasil, desde donde trabaja como crítico teatral del Diário de Lisboa y escribe su obra teatral Mar Alto. A su vuelta, en 1924 , hace sonadas entrevistas a dictadores, militares e intelectuales nacionalistas europeos para $O$ Século y el Diário de Notícias, entre ellos, Mussolinni, Miguel Primo de Rivera, el general Pétain, Gabriele d' Annunzio, o Clemenceau, que fueron recogidas en su libro Viagen à volta das Ditaduras. Su obra política se vería ampliada con Prefácio à República Espanhola (1933), en la que pretende hacer una radiografía de la vida pública española mediante la descripción de algunos de sus intelectuales y políticos más ilustres, como Marcelino Domingo, José Ortega y Gasset, Indalecio Prieto o Miguel de Unamuno. Entonces Ferro ya se sentía identificado con el proyecto salazarista y, en 1932 , publica una serie de entrevistas a Salazar en el Diário de Notícias recogidas en Salazar. O Homem e a sua obra (1933), que alcanzó numerosas ediciones en varios idiomas. En 1933, Ferro es llamado para dirigir el Secretariado de Propaganda Nacional (SPN), a través del que pone en práctica su proyecto de intervención política en el arte y la cultura portuguesa. En 1935, desde el SPN, crea el Cinema Popular Ambulante y, poco después, el Teatro do Povo. Fue director del SPN entre 1933 y 1945, y del Secretariado Nacional de Informação (refundación del SPN) desde entonces hasta 1950.

4 Hipólito Raposo, Alfredo Pimenta, Alberto de Monsaraz, José Pequito Rebelo, Luis Cabral de Moncada, Virgílio Correia, Rolão Preto (posterior líder del Movimento Nacional-Sindicalista Português) entre otros, formaban parte del movimiento integralista, liderado por António Sardinha (1887-1925), de ideas ultranacionalistas, anti-liberales, corporativistas y monárquicas. Sus miembros más destacados eran grandes terratenientes o pequeños aristócratas con formación universitaria, partidarios de un Estado autoritario. El Integralismo Lusitano comenzó siendo una especie de club político con una revista que tenía el mismo nombre y que estaba formado por estudiantes conservadores y monárquicos de la Universidad de Coimbra, que pretendían reaccionar contra la instauración de la República, el 5 de octubre de 1910 . Su principal referencia ideológica era el movimiento de la derecha radical francesa de la Action Française. La Universidad de Coimbra se convirtió en un escenario intelectual para la difusión de sus ideas a través de la revista Nação Portuguesa (1914-1938). Luego, algunos de los miembros del Integralismo Lusitano, encabezados por Rolão Preto, evolucionaron hacia el fascismo y, en febrero de 1932, fundaron en Lisboa $A$ Revolução. La ideología salazarista recicló algunos de los mitos del integralismo y varios de los intelectuales integralistas se alinearon con el Estado Novo en un principio, pero, con el tiempo, muchos se transformaron en disidentes.

5 Júlio Dantas (1876-1962) fue escritor, dramaturgo, médico, diplomático y político. El primero de sus libros fue $\mathrm{Nada}$ (1897), cuya crítica favorable lo catapultó al pedestal de la fama. En 1902, fue nombrado oficial-médico del ejército. En 1908, fue elegido socio-corresponsal de la Academia de Ciências de Lisboa y socio titular en 1913 . Su creciente prestigio intelectual le valió el nombramiento de la seccción de Letras de la citada academia en 1921. Fue parlamentario en varias legislaturas desde la proclamación de la República Portuguesa en 1910. Desempeñó varios cargos públicos y ejerció funciones diplomáticas en Brasil y Londres en los años 20. En 1934, fue nombrado representante de Portugal en el Instituto de Cooperação Intelectual de la Sociedad de Naciones. Colaboró en diversos periódicos portugueses. En los años treinta, era miembro de la Academia de Historia de Madrid y, en 1935, recibió la distinción de "colegial becario" del Colegio San Ildefonso de Alcalá de Henares. Sus méritos académicos le valieron varias condecoraciones internacionales. En su extensa obra podemos recordar los siguientes títulos. Poesía: Sonetos (1916). Prosa: A 
Severa, 1901, Outros tempos (1909), Figuras de ontem e de hoje (1914), Pátria portuguesa (1914), Ao ouvido de Madame X (1915), O amor em Portugal no século XVIII (1915), Mulheres (1916), Contos (1930), Alta Roda (1932), As inimigas do homem (1933), Viagens em Espanha (1936). Teatro: tradujo Cirano de Bergerac, de Rostand, y Leque de Lady Margarida, de Óscar Wilde. Muchas de sus obras fueron traducidas al castellano, francés, italiano, alemán, sueco, japonés y danés. Algunas de ellas fueron llevadas al cine, como $O$ reposteiro verde, producido por Studio Filmes de Barcelona.

\section{BIBLIOGRAFÍA}

Ameal, João. (1956). Anais da Revolução Nacional. Porto: Empresa Editora Majesta, 2 vols.

Bastos, José Timóteo da Silva. (1985). História da Censura Intelectual em Portugal: ensaio sobre a compreensão do pensamento português. Lisboa: Moraes Editores.

Braga da Cruz, Manuel. (1988). O partido e o Estado no salazarismo. Lisboa: Editorial Presença.

Brandão, Fernando de Castro. (2008): Estado Novo. Uma cronologia. Lisboa: Livros Horizonte.

Ferro, António. (1943). Dez Anos de Política do Espírito (1933-1943). Lisboa: Edição do SPN.

Idem. (1978). Salazar. Lisboa: Edições do Templo.

Grácio, Sérgio. (1982). “Escolarização e modos de integração na formação social portuguesa (1950-1978)". Análise Piscológica, no 4, 55-56.

Machado, Bernardino. (1978). Manifestos Políticos (1927-1940). Lisboa: Palas Editores.

Madeira, João. (1996). Os Engenheiros de Almas. O Partido Comunista e os Intelectuais. Lisboa: Estampa.

Martins, Moisés Lemos. (1990). O Olho de Deus no discurso salazarista. Porto: Edições Afrontamento.
6 Jacinto Benavente (1866-1954) nunca fue asesinado. Como tampoco lo fueron otros intelectuales españoles simpatizantes del franquismo que la propaganda portuguesa dio por muertos, como Wenceslao Fernández Flórez. En el caso concreto de Jacinto Benavente, al acabar la guerra, presidió la tribuna de honor en el Desfile de la Victoria de los militares rebeldes en Valencia. António Ferro, sin embargo, persistió en su error en una entrevista concedida al periódico Acção el 3 de octubre de 1936: “(...) Que Jacinto Benavente apareceu entrevistado num jornal depois de nos noticiarem a sua morte? Quem

Matos, Helena. (2010a). Salazar. A Construção do Mito, 1928-1933. Lisboa: Temas e Debates-Círculo de Leitores.

Idem. (2010b). Salazar. A Propaganda, 1934-1938. Lisboa: Temas e DebatesCírculo de Leitores.

Matos e Lemos, Mário. (2006). Jornais Diários Portugueses. Um dicionário. Coimbra, Ariadne Editora.

Oliveira, César. (1988). Salazar e a Guerra Civil de Espanha. Lisboa: Edições O Jornal, 2ª edición.

Paulo, Heloisa. (1994): Estado Novo em Portugal e no Brasil. O SPN/SNI e o DIP. Coimbra: Minerva História.

Pena Rodríguez, Alberto. (2009). O Que Parece É. Salazar, Franco e a Propaganda contra a Espanha Democrática. Lisboa: Tinta da China, 2009.

Idem. (2007). Salazar, a Imprensa e a Guerra Civil de Espanha. Coimbra: MinervaCoimbra.

Idem. (1998). El Gran Aliado de Franco. Portugal y la Guerra Civil española: prensa, radio, cine y propaganda. Sada (A Coruña): Ediciós do Castro.

Ribeiro, Maria Manuela Tavares. (Coord.). (2010). Outros Combates Pela História. Coimbra: Imprensa da Universidade.

Rojas, Carlos. (1995). iMuera la inteligencia! iViva la muerte! Salamanca, 1936. Barcelona: Planeta. não conhecer a Jacinto Benavente e a sua obra, acredita; os que a conhecem, não. Essa entrevista é apócrifa, não é Jacinto Benavente a falar, a escrever a discorrer; nada que se pareça com êle (...)", decía Ferro (Acção, año 1, no 19, 03/1071936, p. 2).

7 Archivo del Ministerio de Asuntos Exteriores, R-135, carpeta no 10. Informe de Roberto Pinto de Queiroz y Melo, secretario de Bernardino Machado y delegado en España del Comité Portugués de Paris, 14/05/1937.

Rosas, Fernando. (Coord.). (1994). História de Portugal. O Estado Novo (19261974). Lisboa: Estampa.

Rosas, Fernando; Brandão de Brito, J. M. (1996). Dicionário de História do Estado Novo. Lisboa: Bertrand, 2 vols.

Salazar, António de Oliveira. (1945). Discursos e Notas Políticas (1935-1937). Coimbra: Coimbra Editora, 2 vols.

Santana, Emídio. (1976). História de um atentado- $O$ atentado a Salazar. Lisboa: Publicações Forum.

Schneider, Luis Mário. (1978). II Congreso Internacional de Escritores Antifascistas (1937). Barcelona: Editorial Laia.

Secretariado de Propaganda Nacional (1939): Portugal ante la Guerra Civil de España. Documentos y notas. Lisboa: SPN.

Torgal, Luis Reis. (2008). Estados Novos, Estado Novo. Coimbra: Imprensa da Universidade.

Idem. (1999). A Universidade e o Estado Novo. Coimbra: Minerva História.

Idem. (2003). "Los intelectuales y el Estado Novo". Studia Historica. Historia Contemporanea, 21, pp. 183-196.

Trapiello, Andrés. (2009). Las armas y las letras. Literatura y guerra civil (19361939). Barcelona: Planeta. 